DOI: $10.36910 / 6775-2524-0560-2019-36-9$

УДК $519.876 .5 ; 621.31 .33$

В.В. Лишук, Й.Р. Селепина, М.М. Свсюк, А.О. Денисюк, Д.М. Трофимчук

Луцький національний технічний університет

\title{
МАТЕМАТИЧНА МОДЕЛЬ ЕЛЕКТРИЧНОЇ ДОВГОЇ ЛІНІЇ З РОЗПОДІЛЕНИМИ ПАРАМЕТРАМИ В СИСТЕМАХ ЗВ'ЯЗКУ
}

\begin{abstract}
В.В. Лишук, Й.Р. Селепина, М.М. Свсюк, А.О. Денисюк, Д.М. Трофимчук. Математична модель електричної довгої лінії з розподіленими параметрами в системах зв'язку. У статті запропоновано математичну модель довгої лінії з розподіленими параметрами. Використано рівняння Максвелла, тобто рівняння електромагнітного поля з частинними похідними, що найповніше відтворюють картину фізичних процесів у елементах передачі енергії. Розв'язок диференціальних рівнянь з частинними похідними реалізується застосуванням числових методів з допомогою комп'ютерної техніки.
\end{abstract}

Ключові слова: математична модель, електрична довга лінія, алгебраїчні та диференціальні рівняння.

В.В. Лышук, И.Р. Селепина, Н.Н. Евсюк, А.О. Денисюк, Д.М. Трофимчук. Математическая модель электрической длинной линии с распределенными параметрами в системах связи. В статье предложена математическая модель электрической длинной линии с распределенными параметрами. Использовано уравнения Максвелла, то есть уравнения магнитного поля в частных производных, что наиболее точно воспроизводят картину физических процессов в элементах передачи энергии. Решение дифференциальных уравнений в частных производных реализируется использованием численных методов с помощью компьютерной техники.

Ключевые слова: математическая модель, электрическая длинная линия, алгебраические и дифференциальные уравнения.

V.V. Lyshuk, Y.R. Selepyna, M.M. Yevsiuk, A.O. Denysiuk, D.M. Trofymchuk. Mathematical model of an electric long line with distributed parameters in communication systems. The article proposes a mathematical model of an electric long line with distributed parameters. The Maxwell equation used, that is the electromagnetic field equation with partial derivatives, which most fully reproduces the picture of physical processes in the elements of energy transfer is involved. The solution of partial differential equations is realized using numerical methods using computer technology.

Keywords: mathematical model, electrical long line, algebraic and differential equations.

Постановка проблеми. Математичне моделювання складних технічних систем різного характеру на сьогоднішній день є важливою технічною задачею. 3 допомогою апарату математичного моделювання можна аналізувати динамічні процеси в різноманітних електротехнічних пристроях $\mathrm{i}$ системах, не використовуючи для цього дороговартісні експерименти.

У нашій праці побудуємо математичну модель довгої лінії телеграфного і телефонного зв’язку на основі законів електромагнітного поля та диференціальних рівнянь 3 частинними похідними [4]. На практиці представлення електротехнічних пристроїв та їх елементів у вигляді кіл з розподіленими параметрами не завжди можливе. Тому тут вдаються до апарату математичного моделювання. Розглядаючи електромагнітні процеси в електричних лініях за допомогою яких електрична енергія або сигнали передаються на відстані, необхідно мати на увазі, що магнітне і електричне поля змінюються як в часі, так і по всій довжині лінії $[1,2]$.

До електричних кіл $з$ розподіленими параметрами відносяться лінії електропередачі (ЛЕП), лінії телеграфного і телефонного зв’язку, радіотрансляційні лініі, лінії телекерування і телевимірювання тощо. Довга лінія - один 3 елементів складних систем. Найчастіше вона зустрічається у вигляді кабелів тої чи іншої конструкції. Ми розглянемо лише двопровідну довгу лінію і покажемо основні особливості математичного моделювання у колах з розподіленими параметрами. Рівняння для напруг і струмів такої лінії загалом придатні і для інших типів ліній, зокрема трифазних [1, 4].

Аналіз досліджень. 3 області кіл 3 розподіленими параметрами найбільший інтерес представляють однорідні лінії, тобто лінії, що мають по всій своїй довжині однакові первинні параметри. Це активний опір, індуктивність, провідність і ємність, що виражаються рівномірно розподіленими уздовж лінії, а $R_{0}, L_{0}, G_{0}, C_{0}$ - значення цих параметрів на одиницю довжини лінії.

У всіх випадках при аналізі перехідних процесів в колах 3 розподіленими параметрами необхідно виходити із системи диференціальних рівнянь в частинних похідних, так званих телеграфних рівнянь при певних початкових і граничних умовах. Тут доречно відзначити, що такі кола 3 постійними розподіленими параметрами є ідеалізацією вихідних положень під час формування математичних моделей електромагнітних процесів [4].

() В.В. Лишук, Й.Р. Селепина, М.М. Свсюк, А.О. Денисюк, Д.М. Трофимчук. 
На рис.1 наведена заступна схема довгої лінії. Слід відмітити, що модель враховуватиме ємнісні струми і струми втрат крізь ізоляцію. Ці струми пропорційні напрузі між проводами.

Крім того, при високих частотах в радіотехнічних пристроях ємнісні струми збільшуються 3 ростом частоти, тобто швидкості зміни напруги.

Однорідну довгу лінію можна розглядати як симетричний чотириполюсник, тобто як $T$-подібну заступну схему.

Якщо умовно виділити яку-небудь кінечну ділянку цієї лінії, то струми на кінцях цієї ділянки будуть неоднаковими із-за наявності струмів зміщення.

Напруга між проводами також неоднакова уздовж лінії. Вона зменшується в напрямку від початку до кінця лінії, оскільки росте спад напруги, обумовлений активним та індуктивним опорами

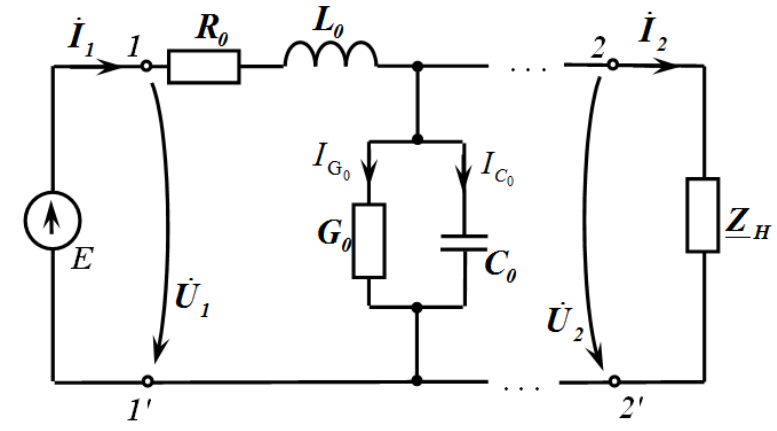

Рис.1. Заступна схема довгої лінії. проводів [3].

Як відомо електромагнітні процеси при високих частотах супроводжуються значним поверхневим ефектом. Однак його врахування у колах з розподіленими параметрами $\epsilon$ досить складною задачею, розв'язання якої можливе лише із застосуванням методів теорії електромагнітного поля. Відомі спроби розв'язання ії аналітично є надто приблизні й не відповідають суті кіл з розподіленими параметрами.

Виклад основного матеріалу й обгрунтування отриманих результатів. Для побудови математичної моделі скористаємось першим і другим рівняннями Максвелла. Вважаючи діелектрик лінійним ізотропним середовищем, запишемо їх у вигляді [3, 4]

$$
\begin{gathered}
\nabla \times \vec{H}=\gamma_{0} \vec{E}+\frac{\partial \vec{D}}{\partial t}=\gamma_{0} \vec{E}+\varepsilon \frac{\partial \vec{E}}{\partial t} ; \\
\nabla \times \vec{E}=-\frac{\partial \vec{B}}{\partial t}=-\mu_{0} \frac{\partial \vec{H}}{\partial t}
\end{gathered}
$$

де $\vec{H}, \vec{E}$ - відповідно вектори магнітного та електричного полів, $\mu_{0}, \gamma_{0}, \varepsilon-$ відповідно магнітна проникність, електропровідність й діелектрична проникність діелектрика, $\nabla=\frac{\partial}{\partial x} x_{0}+\frac{\partial}{\partial \alpha} \alpha_{0}+\frac{\partial}{\partial r} r_{0}-$ оператор набла [2].

У циліндричній системі вектори напруженостей електромагнітного поля $\vec{E}$ і $\vec{H}$ можна виразити через аксіальні і радіальні компоненти

$$
\vec{E}=x_{0} E_{x}+r_{0} E_{r} ; \quad \vec{H}=\alpha_{0} H_{\alpha}+r_{0} H_{r},
$$

де $x_{0}, \alpha_{0}, r_{0}-$ орти.

3 урахуванням (3) аксіальні та радіальні складові у рівняннях (1), (2) набувають вигляду

$$
\begin{aligned}
& \frac{\partial H_{\alpha}}{\partial x}=\gamma_{0} E_{r}+\varepsilon \frac{\partial E_{r}}{\partial t} . \\
& \frac{\partial E_{r}}{\partial x}-\frac{\partial E_{x}}{\partial r}=-\mu_{0} \frac{\partial H_{\alpha}}{\partial t} .
\end{aligned}
$$

Напругу між проводами знайдемо, проінтегрувавши радіальну складову вектора напруженості електричного поля по відстані

$$
u=\int_{R}^{D-R} E_{r} d r
$$

() В.В. Лишук, Й.Р. Селепина, М.М. Євсюк, А.О. Денисюк, Д.М. Трофимчук. 
де $R$ - радіус проводів; $D$ - відстань між осями проводів.

Вважаючи, що геометричні й електричні осі проводів збігаються, значення напруженості $E_{r}$ уздовж траєкторії, що збігається 3 найкоротшою відстанню між осями проводів, знаходимо згідно постулату Максвелла

$$
E_{r}=\frac{\tau}{2 \pi \varepsilon r}+\frac{\tau}{2 \pi \varepsilon(D-r)}
$$

де $\tau$ - лінійна густина заряду.

Значення аксіальної складової вектора напруженості магнітного поля $H_{\alpha}$ уздовж цієї самої траєкторії визначаємо за законом повного струму [4]

$$
H_{\alpha}=\frac{i}{2 \pi r}+\frac{i}{2 \pi(D-r)} .
$$

Помножимо (5) на $d r$ і проінтегруємо отриманий результат у межах від $R$ до $D-R$. Переставивши місцями символи диференціювання й інтегрування, матимемо

$$
-\frac{\partial}{\partial x} \int_{R}^{D-R} E_{r} d r=-\int_{R}^{D-R} \frac{\partial E_{x}}{\partial r} d r+\mu_{0} \frac{\partial}{\partial t} \int_{R}^{D-R} H_{\alpha} d r .
$$

Беручи до уваги (6) та підставляючи (7) у (8), після інтегрування отримуємо

$$
-\frac{\partial u}{\partial x}=2 E_{x}(R)+L_{0} \frac{\partial i}{\partial t}
$$

де

$$
L_{0}=\frac{\mu_{0}}{\pi} \ln \frac{D}{R}
$$

Величина $L_{0}$ згідно 3 вибраними межами інтегрування - це зовнішня індуктивність лінії на одиницю довжини (погонна індуктивність). Щодо внутрішньої індуктивності й електричного опору пари проводів, то їхню дію відображає доданок $2 E_{x}(R)$ на поверхні проводу.

Перший доданок у правій частині (10) отриманий за умови, що значення аксіального компонента вектора напруженості електричного поля однакове на поверхні обох проводів. Однак ця умова не завжди виконується. Наприклад, у випадку коаксіального кабеля маємо

$$
-\frac{\partial u}{\partial x}=E_{x}\left(R_{1}\right)-E_{x}\left(R_{2}\right)+L_{0} \frac{\partial i}{\partial t}
$$

де $R_{1}$ - зовнішній радіус внутрішньої жили; $R_{2}$ - внутрішній радіус зовнішньої жили. 3 цієї точки зору вираз (12) узагальнює (10).

Рівняння (10), (12) складніші за відоме телеграфне рівняння довгої лінії. Його інтегрування пов'язано з обчисленням тангенціального компонента вектора $E$ на поверхні проводу, що вимагає інтегрування рівнянь (4), (5) у тілі одного з проводів при використанні рівняння (10).

У разі розрахунку поля в тілі проводів другим доданком у правій частині (5) нехтуємо. Тоді

$$
\frac{\partial H_{\alpha}}{\partial t}=\frac{v_{0}}{\gamma}\left(\frac{\partial^{2} H_{\alpha}}{\partial x^{2}}+\frac{\partial^{2} H_{\alpha}}{\partial r^{2}}+\frac{1}{r} \frac{\partial H_{\alpha}}{\partial r}-\frac{H_{\alpha}}{r^{2}}\right),
$$

де $\gamma$ - електропровідність матеріалу проводу, $v_{0}=1 / \mu_{0}$ - релактивність діелектрика.

Початкові умови рівняння (13) вважаємо відомими з розрахунку попереднього режиму. Крайові умови стосовно (12) знаходимо за законом повного струму

$$
H_{\alpha}(0, x, t)=0, H_{\alpha}\left(R_{1}, x, t\right)=i(x, t) /\left(2 \pi R_{1}\right) ; \quad H_{\alpha}\left(R_{2}, x, t\right)=i(x, t) /\left(2 \pi R_{2}\right) ; H_{\alpha}\left(R_{3}, x, t\right)=0,
$$

де $R_{3}$ - зовнішній радіус зовнішньої жили, $x$ - координата довжини.

Нехтуючи вихровими струмами у зосереджених елементах, що межують 3 лінією, маємо: 


$$
\left.\frac{\partial H_{\alpha}}{\partial x}(r, x, t)\right|_{\substack{x=0 \\ x=l}}=0 .
$$

Значення $E_{x}\left(R_{1}\right), E_{x}\left(R_{2}\right)$ знаходимо, якщо знехтувати другим доданком в рівнянні (1), тобто струмами зміщення і врахувавши (3)

$$
E\left(R_{i}\right)=\left.\frac{1}{\gamma}\left(\frac{\partial H}{\partial r}+\frac{H}{r}\right)\right|_{r=R_{i}}, \quad i=1,2 .
$$

Підставимо (7) у (6) та проінтегруємо отриманий результат

$$
u=\frac{\tau}{\pi \varepsilon} \ln \frac{D}{R} .
$$

Із (7), (17) одержуємо

$$
E_{r}=\frac{u}{2 r \cdot \ln \frac{D}{R}} .
$$

Підставляючи (8), (18) у (5), одержуємо відоме телеграфне рівняння

$$
-\frac{\partial i}{\partial x}=g_{0} u+C_{0} \frac{\partial u}{\partial x}
$$

де $g_{0}, C_{0}$ - провідність витоку та ємність на одиницю довжини (погонні провідність і ємність)

$$
g_{0}=\frac{\pi \gamma_{0}}{\ln \frac{D}{R}} ; \quad C_{0}=\frac{\pi \varepsilon}{\ln \frac{D}{R}} .
$$

Формули (17), (18) одержані за умови $D>>R$.

У випадку коаксіального кабелю рівняння (6) набуває вигляду

$$
u=\int_{R_{1}}^{R_{2}} E_{r} d r .
$$

Тоді вирази (7), (8) спрощуються:

$$
E_{r}=\frac{\tau}{2 \pi \varepsilon r} ; \quad H_{\alpha}=\frac{i}{2 \pi r} .
$$

Рівняння (19) залишається без зміни, але $g_{0}, C_{0}$ мають інший вигляд ніж у (20):

$$
g_{0}=\frac{2 \pi \gamma_{0}}{\ln \frac{R_{2}}{R_{1}}} ; \quad C_{0}=\frac{2 \pi \varepsilon}{\ln \frac{R_{2}}{R_{1}}} .
$$

Вирази (10), (13), (19) - диференціальні рівняння двопровідної лінії, що враховують поверхневий ефект у проводах. У практичних розрахунках рівняння (10), (19) інколи доцільно подати одним рівнянням. Диференціюючи перше з них за $t$, а друге за $x$, отримуємо

$$
a_{1} \frac{\partial^{2} i}{\partial t^{2}}+a_{2} \frac{\partial i}{\partial t}=\frac{\partial^{2} i}{\partial x^{2}}-a_{3} E_{x}\left(R_{1}\right)-a_{4} \frac{\partial E_{x}}{\partial t}\left(R_{1}\right),
$$

де $a_{1}=L_{0} C_{0}, a_{2}=g_{0} L_{0}, a_{3}=2 g_{0}, a_{4}=2 C_{0}$.

Рівняння (24) описує просторово-часовий розподіл струму вздовж лінії. Щоб проінтегрувати його, необхідно знати початкові $i(x, 0)$ і крайові умови. Початкові умови вважаємо відомими (нульовими), а крайові знаходимо виходячи з (19): 


$$
\left.\frac{\partial i}{\partial x}\right|_{\substack{x=0 \\ x=l}}=\left.\left(g_{0} u+C_{0} \frac{\partial u}{\partial t}\right)\right|_{\substack{x=0 \\ x=l}} .
$$

Електрична напруга на початку лінії відома. У кінці лінії ії визначаємо з рівнянь споживача

$$
u(l, t)=L \frac{\partial i_{l}}{\partial t}+R i_{l}+u_{C} ; \quad i_{l}=C \frac{\partial u_{C}}{\partial t},
$$

де $R, L, C$ - опір, індуктивність і ємність споживача; $u_{C}$ - напруга конденсатора.

Розв'язування (24) на першому кроці інтегрування здійснюємо згідно з (10).

Вирази (10), (13), (16), (24) за крайових умов (14), (15), (25) утворюють повну систему диференціальних рівнянь довгої лінії. Інтегруємо їх сумісно з рівняннями споживача (26). Скінченнорізницеву апроксимацію цих рівнянь здійснюємо за явним принципом [2]. У першому випадку для забезпечення стійкості розв'язання необхідно дотримуватися умови Куранта [2, 4]

$$
\Delta t<\min \left(\mu \gamma \frac{(\Delta r)^{2}}{2}, \sqrt{L_{0} C_{0}} \Delta x\right),
$$

де $\Delta t, \Delta r, \Delta x$ - кроки інтегрування по часу $t$, радіусу $r$ і довжині $x$.

На рис.2, 3 зображено переріз модельованого коаксіального кабелю і наведено результати розрахунку перехідного процесу в ньому, а саме розподіли напруги $(1,3)$ і струму $(2,4)$ вздовж лінії в момент часу $t=0,907 \cdot 10^{-3} \mathrm{c}$. у станах активного навантаження 3 опором $R=10$ Ом $(1,2)$ і короткого замикання $(3,4)$ при вмиканні кабелю на джерело напруги $u=100 \sin \omega t$. Частота напруги $f=5$ МГц. Інтегрування рівнянь проведено за явним принципом у середовищі FORTRAN FORCE 2.0. Графічні залежності побудовано в редакторі GRAPHER.

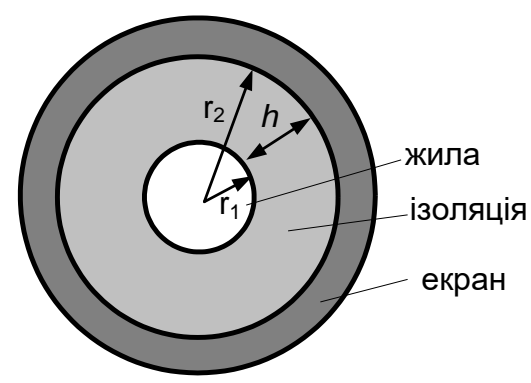

Рис.2. Переріз коаксіального кабелю.

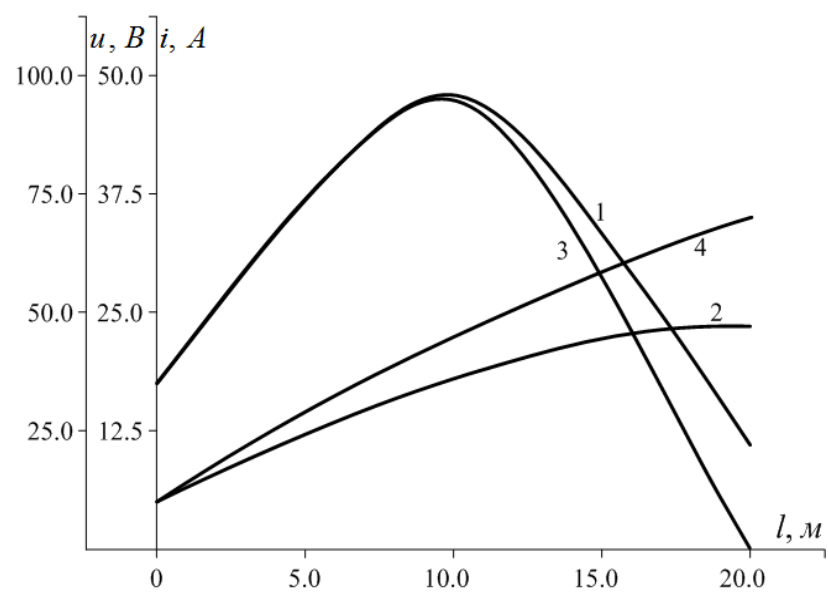

Рис.3. Розподіли напруги $(1,3)$ і струму $(2,4)$ в станах активного навантаження $(1,2)$ і короткого замикання $(3,4)$.

В області радіочастот, так як у нашому випадку, первинні параметри однорідної двопровідної лінії з мідними проводами для коаксіального кабелю можуть бути визначені на відміну від (20) за формулами

$$
\begin{aligned}
& r_{0}=4,16 \sqrt{f}\left(\frac{R_{1}+R_{2}}{R_{1} \cdot R_{2}}\right) \cdot 10^{-8}, O M / \mathcal{M} ; \quad g_{0}=\omega \cdot C_{0} \cdot \operatorname{tg} \delta \approx \pi f C_{0} \cdot 10^{-4}, C_{M} / \mathcal{M} ; \\
& C_{0} \approx \frac{0,241 \varepsilon}{\lg \frac{R_{2}}{R_{1}}} \cdot 10^{-10} \Phi / \mathcal{M} ; \quad L_{0} \approx 0,46 \lg \frac{R_{2}}{R_{1}} \cdot 10^{-6} \Gamma_{H} / \mathcal{M} .
\end{aligned}
$$

В обчисленнях були задіяні такі параметри лінії (кабелю): $R_{1}=0,0007 \mathrm{M}, R_{2}=0,0018 \mathrm{~m} ; l=20 \mathrm{M}$; $L_{0}=0,2 \cdot 10^{-6} \Gamma \mathrm{H} / \mathrm{M} ; r_{0}=0,2$ Oм$/ \mathrm{m} ; g_{0}=0,18 \cdot 10^{-6} \mathrm{CM} / \mathrm{M} ; C_{0}=100 \cdot 10^{-12} \Phi / \mathrm{M} ; \gamma_{C u}=58 \cdot 10^{6} \mathrm{CM} / \mathrm{M}$. 
Висновки. Побудовано математичну модель довгої лінії, що дає змогу здійснювати аналіз електричних кіл 3 розподіленими параметрами і встановити в аналітичному вигляді залежності напруг та струмів від просторової та часової координат. Така модель дає змогу оцінити перехідні процеси в довгих лініях з різними видами навантажень.

\section{Список бібліографічних посилань}

1. Байдак Ю.В. Основи теорії кіл. Навч. посібник / Ю.В. Байдак. - К.: Вища шк.: Слово, 2009. - 271 с.

2. Зеленський К. Х. Комп'ютерні методи прикладної математики / К. Х. Зеленський, В. М. Ігнатенко, . П. Коц. - К.: Академперіодика, 2002. - 480 с.

3. Иваницкий А.М. Телеграфные уравнения однородных линий при экспофункциональных сигналах / А.М. Иваницкий, М.В. Рожновский // Наукові праці ОНАЗ ім. О.С. Попова. - 2009. - №1 - С.56-63.

4. Чабан В.Й. Електромагнетне поле / В.Й. Чабан. - Львів: В-во Т. Сороки, 2006. - 394 с.

1. Baidak Yu.V. Fundamentals of Circle Theory. Educ. manual / Yu.V. Kayak. - K .: Higher School: Word, 2009. - 271 p.

2. K. Zelensky, Computer Methods in Applied Mathematics / K. Kh. Zelensky, V. M. Ignatenko,. P. Kotz. - K .: Akademperiodika, 2002. $-480 \mathrm{p}$

3. Ivanitsky AM Telegraphic equations of homogeneous lines at expofunctional signals / A.M. Ivanitz-ciy, M.V. Rozhnovsky // Scientific works of ONAZ them. OS Popova. - 2009. - №1. - P.56-63.

4. Chaban VY Electromagnetic field / V.Yu. Shepherd. - Lviv: In T. Soroki, 2006. - 394 p 